\title{
Cardiac dysfunction as an early predictor of portal hypertension in chronic hepatitis $C$
}

\author{
Cecilia Marconia, Mattia Bellann, ${ }^{\mathrm{b}, c}$, Paola Giardaa,c, Rosalba Minisinia, Serena Favretto ${ }^{a}$, \\ Michela Emma Burlone ${ }^{a, b, d}$, Lisa Franzosia , Mario Pirisia ${ }^{a, b}$ \\ AOU Maggiore della Carità; Università del Piemonte Orientale UPO; Sant’ Andrea Hospital; CRRF Mons. Luigi \\ Novarese, Italy
}

\begin{abstract}
Background Cirrhotic cardiomyopathy is characterized by a set of cardiovascular modifications observed in advanced chronic liver disease. The aim of this study was to investigate cardiovascular alterations in chronic liver disease with different stages of fibrosis and to correlate cardiac involvement with endoscopic complications of portal hypertension.

Methods Seventy patients with chronic hepatitis C-related chronic liver disease and 20 sex- and age-matched controls underwent clinical evaluation, hepatic transient elastography, and echocardiography. Forty-nine of the 70 patients underwent an esophagogastroduodenoscopy for screening of esophageal and gastric varices.

Results According to the value of liver stiffness (LS), patients were divided in 2 groups: noncirrhotics (LS $<12.5 \mathrm{kPa} ; \mathrm{n}=30$; median $\mathrm{LS}=8.1 \mathrm{kPa}, 95 \%$ confidence interval [CI] 6.4-9.2 $\mathrm{kPa}$ ) and cirrhotics (LS>12.5 kPa; $\mathrm{n}=40$; median LS=19.4 kPa, 95\%CI 17-22 kPa). Compared to noncirrhotics, cirrhotics showed a significant dilatation of the left atrium $(\mathrm{P}=0.007$ and $\mathrm{P}=0.003$ for area and volume index, respectively). In patients with chronic liver disease, peak systolic wave velocity $\left(\mathrm{S}^{\prime}\right)$ measured by tissue Doppler imaging (TDI) was lower $(\mathrm{P}=0.004)$, but ejection fraction was not reduced. Left atrial volume, left ventricular mass index and TDI $S^{\prime}$-wave velocity, but not liver stiffness, correlated with endoscopic signs of portal hypertension.

Conclusions Left atrial enlargement and peak $\mathrm{S}^{\prime}$-wave systolic velocities are echocardiographic markers of diastolic and systolic dysfunction in liver cirrhosis. Cardiac alterations closely correlate to endoscopic portal hypertension; further studies could elucidate the potential role of echocardiography in the early identification of cirrhotic patients at higher risk for endoscopic complications of portal hypertension.
\end{abstract}

Keywords Cirrhotic cardiomyopathy, portal hypertension, echocardiography, hepatitis C

Ann Gastroenterol 2017; 30 (6): 1-7

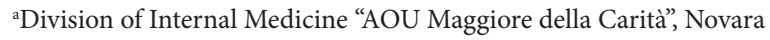
(Cecilia Marconi, Paola Giarda, Rosalba Minisini, Serena Favretto, Michela Emma Burlone, Liza Franzosi, Mario Parisi); 'Department of Translational Medicine, Università del Piemonte Orientale UPO, Novara (Mattia Bellan, Michela Emma Burlone, Mario Parisi); 'Division of Internal Medicine "Sant' Andrea" Hospital, Vercelli (Mattia Bellan, Paola Giarda); ${ }^{\mathrm{d} C R R F}$ "Mons. Luigi Novarese”, Moncrivello, Vercelli (Michela Emma Burlone), Italy

Conflict of Interest: None

Correspondence to: Dr. Mattia Bellan, Department of Translational Medicine, Università del Piemonte Orientale UPO, via Solaroli 17, Novara (NO), 28100, Italy, email: bellanmattia@yahoo.it

Received 28 May 2017; accepted 27 July 2017; published online 6 September 2017

DOI: https://doi.org/10.20524/aog.2017.0190

\section{Introduction}

Cirrhotic cardiomyopathy is a type of chronic cardiac dysfunction observed in patients with cirrhosis; it is characterized by blunted contractile responsiveness to stress and/or altered diastolic relaxation with electrophysiological abnormalities, in the absence of any other known cause of cardiac disease [1]. Systolic dysfunction is the result of an impaired sensitivity to sympathetic activation, leading to a blunted increase in cardiac output and decreased contractility with exercise, pharmacological stress, and volume challenge [2]. Diastolic dysfunction in cirrhotic patients has been associated with increased left ventricular (LV) wall thickness, subendocardial edema, fibrosis and altered collagen structure, ultimately leading to altered relaxation [3]. Finally, 
electrophysiological abnormalities have been observed, including QTc prolongation and impaired electromechanical coupling [4].

With regard to the pathogenesis, it has been postulated that the marked splanchnic arterial vasodilatation observed in liver cirrhosis is initially compensated for by a hyperdynamic circulation; later, the progression of liver disease and portal hypertension leads to further splanchnic vasodilatation and reduction of the effective arterial blood volume, leading to activation of the renin-angiotensin-aldosterone system and the sympathetic nervous system. The overexposure to sympathetic effector molecules leads to myocardial injury, receptor internalization and downregulation, resulting in an impaired response of $\beta$-adrenergic receptors [5-9]. The increased production of endogenous cardiodepressant mediators, such as nitric oxide, carbon monoxide, endogenous cannabinoids and inflammatory cytokines, has also been proposed as a possible causative mechanism [10-12].

Cardiovascular changes in cirrhosis have prognostic implications [13-15]. Therefore, the evaluation of subclinical cardiac involvement could contribute to the early detection of those cirrhotic patients at higher risk of decompensation and development of complications, allowing better tailoring of follow up.

The present study aimed to evaluate the relationship between cirrhotic cardiomyopathy investigated by standard echocardiography, and the severity of liver fibrosis evaluated by transient elastography, in a group of patients affected by hepatitis $\mathrm{C}$ virus ( $\mathrm{HCV}$ )-related chronic liver disease at different stages of fibrosis. In addition, we aimed to investigate the correlation between the echocardiographic findings and endoscopic complications of portal hypertension.

\section{Patients and methods}

A consecutive series of patients with HCV-related chronic liver disease was studied. HCV infection was established by positive serology for HCV and quantifiable HCV RNA over the 6 months prior to recruitment. We excluded patients suffering from liver disease of viral etiology other than HCV, or from decompensated cirrhosis complicated by ascites, hepatopulmonary or hepatorenal syndrome, or portal-systemic encephalopathy. Patients with a history of cardiovascular disease, including ischemic cardiomyopathy, atrial fibrillation, severe valvular defects, severe arterial hypertension or previous hospitalizations for heart failure, were also excluded.

A total of 70 patients and 20 healthy controls were enrolled. All patients underwent a thorough clinical and laboratory evaluation. Patients' data were recorded according to local ethical guidelines.

\section{Clinical evaluation}

Patients provided a detailed clinical history. Cardiovascular risk factors and ongoing treatments were recorded. On physical examination, heart rate and blood pressure were measured. Blood pressure was measured by sphygmomanometer and the mean arterial pressure was calculated according to the formula: diastolic pressure + (systolic pressure - diastolic pressure)/3. Weight and height were measured without shoes and in light underwear, and body mass index was calculated as: weight $(\mathrm{kg}) /$ height $(\mathrm{m})^{2}$.

\section{Liver fibrosis staging}

Liver stiffness (LS) was measured by transient elastography, performed on the same day of echocardiographic examination, following the manufacturer's instructions (Echosens, Paris, France). A threshold of $12.5 \mathrm{kPa}$ was chosen [16] to distinguish non-cirrhotic patients (Group A; LS $<12.5 \mathrm{KPa}$; $=30$ ) from cirrhotics (Group B; LS $\geq 12.5 \mathrm{kPa}, \mathrm{n}=40$ ); the control group was defined as Group C.

\section{Electrocardiographic evaluation}

A 12-lead electrocardiogram was recorded for each patient and the QTc interval was estimated according to Bazett's formula: QTc=QTmax $/ \sqrt{ } \mathrm{RR}$ interval.

\section{Echocardiography and esophagogastroduodenoscopy (EGD)}

Echocardiography was performed by an experienced operator in accordance with the recommendations of the American Society of Echocardiography (ASE), using a Logiq S8 (GE Healthcare) system operating with a $3.5 \mathrm{MHz}$ transducer. From a long-axis parasternal view, the LV systolic and diastolic septal wall thicknesses (SWTs and SWTd) and posterior wall thicknesses (PWTs and PWTd), and the left atrial (LA) and LV diameters were measured in M-mode. The LV mass and LV geometry were calculated according to the ASE Convention [17]. LV volumes and ejection fraction were estimated using Simpson's modified biplane method. LA endsystolic volume was calculated using the monoplane method in apical 4-chamber views. The same views were used to derive LA area by the area-length method. Pulsed Doppler examination of the LV inflow was performed with the sample volume placed between the mitral leaflet tips. The following parameters were recorded and measured: peak early (E wave) and atrial (A wave) flow velocities, their ratio $\mathrm{E} / \mathrm{A}$, and the E-wave deceleration time. Tissue Doppler imaging (TDI) was performed from the 4-chamber apical view and tissue velocity was calculated. The myocardial peak systolic velocity $\left(S^{\prime}\right)$ was measured in the lateral and septal mitral annulus to define systolic function. Tissue velocities were also measured in the lateral mitral annulus during the diastole to obtain peak myocardial velocities during early $\left(E^{\prime}\right)$ and atrial filling $\left(A^{\prime}\right)$ phases. To evaluate ventricular filling pressure the $\mathrm{E} / \mathrm{E}^{\prime}$ ratio was also calculated. The ASE 2009 definitions of systolic and diastolic function were used. 
Of the 70 patients, depending on clinical indications, 49 underwent EGD for screening of esophageal and gastric varices in the 2 years prior to recruitment. Twenty-four patients showed normal endoscopic findings, while in 25 patients either esophageal varices or congestive gastropathy were shown.

All patients were informed about the opportunity of being included in the study. The study was approved by the Local Ethics Committee.

\section{Statistical analysis}

The software used for statistical analysis was MedCalc Rel. 9.3.8.0 (MedCalc Software, Broekstraat 52, 9030 Mariakerke, Belgium). The distribution of data was analyzed by the normality test of D’Agostino-Pearson. Continuous variables are reported as medians (95\% confidence interval [CI]) and categorical variables as frequencies (\%). The statistical tests used were the Mann-Whitney test, the Kruskal-Wallis test, the Fisher's exact test, and the chi-square test as appropriate.
Correlations were explored by logistic and linear regression analyses. For all statistical tests, a level of 0.05 (two-tailed) was chosen to define statistical significance.

\section{Results}

\section{Patients' characteristics}

We report the clinical characteristics of the study population in Table 1. Patients were classified, as explained above, according to LS measured by liver transient elastography; controls and patients were comparable for all the clinical variables considered, except for the prevalence of Type 2 diabetes mellitus, which was higher in patients with advanced liver disease. Consequently, a higher proportion of anti-diabetic therapy was reported in this subgroup of patients. In addition, the patients were more frequently taking antihypertensive drugs, especially $\beta$-blockers.

Table 1 Characteristics of the population

\begin{tabular}{|c|c|c|c|c|c|}
\hline \multirow[t]{2}{*}{ Characteristics } & \multirow{2}{*}{$\begin{array}{c}\begin{array}{c}\text { Group A } \\
(\mathrm{HCV}+)\end{array} \\
\begin{array}{c}\text { Stiffness }<12.5 \mathrm{kPa} \\
(\mathrm{n}=30)\end{array}\end{array}$} & \multirow{2}{*}{$\begin{array}{c}\begin{array}{c}\text { Group B } \\
(\mathrm{HCV}+)\end{array} \\
\begin{array}{c}\text { Stiffness }>12.5 \mathrm{kPa} \\
(\mathrm{n}=40)\end{array}\end{array}$} & \multirow{2}{*}{$\begin{array}{c}\begin{array}{c}\text { Group C } \\
\text { (Controls) }\end{array} \\
(\mathrm{n}=20)\end{array}$} & \multicolumn{2}{|c|}{$\mathrm{P}$} \\
\hline & & & & $A+B$ vs. $C$ & A vs. $B$ vs. $C$ \\
\hline Age (years) & $64(54-67)$ & $64(60-70)$ & $58(54-65)$ & 0.17 & 0.19 \\
\hline $\operatorname{Sex}(M / F)$ & $16 / 14$ & $25 / 15$ & $10 / 10$ & 0.61 & 0.59 \\
\hline BMI $\left(\mathrm{kg} / \mathrm{m}^{2}\right)$ & $24(23-27)$ & $25(24-26)$ & $25(23-28)$ & 0.90 & 0.70 \\
\hline MAP (mmHg) & $99(94-106)$ & $97(92-102)$ & $95(90-100)$ & 0.08 & 0.08 \\
\hline HR (bpm) & $81(75-88)$ & $74(70-79)$ & $74(67-80)$ & 0.42 & 0.05 \\
\hline Hypertension $(\mathrm{y} / \mathrm{n})$ & $9 / 30(30 \%)$ & $19 / 40(52 \%)$ & $8 / 20(40 \%)$ & 1 & 0.33 \\
\hline $\mathrm{T} 2 \mathrm{DM}(\mathrm{y} / \mathrm{n})$ & $3 / 30(10 \%)$ & $12 / 40(30 \%)$ & $1 / 20(5 \%)$ & 0.10 & 0.02 \\
\hline Smoking $(y / n)$ & $13 / 30(43 \%)$ & $22 / 40(55 \%)$ & $6 / 20(30 \%)$ & 0.12 & 0.44 \\
\hline Antihypertensive drugs $(\mathrm{y} / \mathrm{n})$ & $9 / 30(35 \%)$ & $27 / 40(67 \%)$ & $7 / 20(30 \%)$ & 0.21 & 0.003 \\
\hline$\beta$-blockers & $4 / 30(13 \%)$ & $15 / 40(38 \%)$ & $0 / 20(0 \%)$ & 0.005 & 0.001 \\
\hline ACEi/ARB & $6 / 30(20 \%)$ & $15 / 40(38 \%)$ & $4 / 20(20 \%)$ & 0.57 & 0.18 \\
\hline $\mathrm{Ca}-\mathrm{CH}$ antagonists & $2 / 30(7 \%)$ & $4 / 40(10 \%)$ & $5 / 20(25 \%)$ & 0.06 & 0.13 \\
\hline Diuretics/TZD & $3 / 30(10 \%)$ & $8 / 40(20 \%)$ & $0 / 20(0 \%)$ & 0.11 & 0.07 \\
\hline Diuretics risp. K & $0 / 30(0 \%)$ & $4 / 40(10 \%)$ & $0 / 20(0 \%)$ & 0.57 & 0.07 \\
\hline Hypoglycemic drugs & $3 / 30(30 \%)$ & $11 / 40(27 \%)$ & $1 / 20(2 \%)$ & 0.17 & 0.04 \\
\hline Insulin & $1 / 30(3 \%)$ & $9 / 40(22 \%)$ & $0 / 20(0 \%)$ & 0.10 & 0.008 \\
\hline Stiffness (KPa) & $8.1(6.4-9.2)$ & $19.4(17-22)$ & $4.3(3.8-5.3)$ & $<0.00001$ & $<0.00001$ \\
\hline IQR (KPa) & $0.65(0.4-1)$ & $3(2.3-4)$ & $0.65(0.4-1)$ & $<0.00001$ & $<0.00001$ \\
\hline SR (\%) & 100 & 100 & 100 & 0.33 & 0.39 \\
\hline
\end{tabular}

The data for continuous variables are presented as median (95\% confidence interval), categorical variables as frequencies (\%). The statistical tests used were the Mann-Whitney test, the Kruskal-Wallis test, the Fisher exact test, and the chi-square test as appropriate

BMI, body mass index; MAP, mean arterial pressure; HR, heart rate; T2DM, Type 2 diabetes mellitus; ACEi, angiotensin-converting enzyme inhibitors, $A R B$, angiotensin receptor blockers; $y / n$, yes/no; IQR, interquartile range; SR, success rate; bpm, beats per minute 


\section{Echocardiographic findings}

As shown in Table 2, patients with LS $>12.5 \mathrm{kPa}$ had a significantly larger left atrium than patients with $\mathrm{LS}<12.5 \mathrm{kPa}$ and controls, whether measured as anterior-posterior (AP) diameter $(\mathrm{P}=0.03)$ or as area and volume index $(\mathrm{P}=0.007$ and $\mathrm{P}=0.003$, respectively). Furthermore, LS $>12.5 \mathrm{kPa}$ was the only independent predictor of LA dilatation (Table 3). LV diameters, thicknesses and volumes did not differ significantly between groups, although a tendency towards larger cardiac mass index, LV volume and wall thickness was observed in the group of patients with advanced fibrosis. All groups showed an LV ejection fraction within the normal range and mild diastolic dysfunction, according to the ASE Guidelines, while the peak systolic velocities recorded with TDI $\left(S^{\prime}\right)$ were significantly lower in patients with LS suggestive of liver cirrhosis (Table 2).

\section{Electrophysiological abnormalities}

We observed longer QTc intervals among patients with HCV-related liver disease: Group C: $410.0 \mathrm{msec}$ (397.5-428.5) vs. Group A 432.5 msec (416.0-459.6) vs. Group B 434.0 msec (418.0-444.0). However, the median values were still lower than the upper reference limits of normal (440 msec). QTc interval prolongation was not related to LS>12.5 Kpa $(\mathrm{P}=0.85)$.

\section{EGD findings}

Forty-nine patients had undergone endoscopy within two years prior to recruitment; of these, 25 patients showed abnormal endoscopic findings (esophageal varices F1 to F4 and/or congestive gastropathy). As shown in Table 4, LS was significantly higher in patients with endoscopic signs of portal hypertension, while the peak systolic velocity, recorded as the TDI $S^{\prime}$ wave at the mitral annulus, was significantly lower. Logistic regression confirmed that the $S^{\prime}$ wave measured by TDI was the only independent predictor of the presence of endoscopic signs of portal hypertension (Table 5). We further considered a cutoff value for LS of $19 \mathrm{kPa}$, previously described as highly predictive for the diagnosis of large esophageal varices [18], according to which we built a further model.

Table 2 Echocardiographic parameters

\begin{tabular}{|c|c|c|c|c|c|}
\hline \multirow[t]{2}{*}{ Parameters } & \multirow{2}{*}{$\begin{array}{c}\begin{array}{c}\text { Group A } \\
(\mathrm{HCV}+)\end{array} \\
\begin{array}{c}\text { Stiffness }<12.5 \mathrm{Kpa} \\
(\mathrm{n}=30)\end{array}\end{array}$} & \multirow{2}{*}{$\begin{array}{c}\begin{array}{c}\text { Group B } \\
(\mathrm{HCV}+)\end{array} \\
\begin{array}{c}\text { Stiffness }>12.5 \mathrm{Kpa} \\
(\mathrm{n}=40)\end{array}\end{array}$} & \multirow{2}{*}{$\begin{array}{c}\begin{array}{c}\text { Group C } \\
\text { (controls) }\end{array} \\
(\mathrm{n}=20)\end{array}$} & \multicolumn{2}{|c|}{$\mathrm{P}$} \\
\hline & & & & $A+B$ vs. $C$ & A vs. B vs. C \\
\hline LA diameter $(\mathrm{cm})$ & $3.81(3.5-4)$ & $4(3.7-4.4)$ & $3.6(3.4-4)$ & 0.12 & $0.03^{*}$ \\
\hline LA area $\left(\mathrm{cm}^{2}\right)$ & $17(16-19)$ & $20(18-21)$ & $17(16-19)$ & 0.14 & $0.02^{*}$ \\
\hline LA volume index $\left(\mathrm{mL} / \mathrm{m}^{2}\right)$ & $24(19-26)$ & $30(26-34)$ & $23(20-27)$ & 0.16 & $0.003^{*}$ \\
\hline End-diastolic LV diameter $(\mathrm{cm})$ & $4.6(4.3-4.9)$ & $4.6(4.5-4.9)$ & $4.9(4.4-5)$ & 0.34 & 0.47 \\
\hline RWT & $0.44(0.40-0.46)$ & $0.47(0.42-0.49)$ & $0.43(0.41-0.46)$ & 0.49 & 0.57 \\
\hline $\mathrm{LV}$ indexed mass $\left(\mathrm{g} / \mathrm{m}^{2}\right)$ & $97(92-105)$ & $105(91-110)$ & $96(91-102)$ & 0.31 & 0.27 \\
\hline End-diastolic LV volume (mL) & $100(78-112)$ & $112(96-124)$ & $98(87-107)$ & 0.43 & 0.16 \\
\hline Ejection fraction (\%) & $65(62-67)$ & $64(61-65)$ & $65(63-66)$ & 0.45 & 0.29 \\
\hline Interventricular septum $(\mathrm{cm})$ & $1(0.9-1.1)$ & $1.1(1-1.2)$ & $1(0.9-1.1)$ & 0.18 & 0.06 \\
\hline Posterior wall $(\mathrm{cm})$ & $1(0.9-1.1)$ & $1.1(1-1.2)$ & $1(1-1.1)$ & 0.45 & 0.65 \\
\hline E wave $(\mathrm{m} / \mathrm{sec})$ & $70(60-73)$ & $60(56-66)$ & $63(56-65)$ & 0.54 & 0.28 \\
\hline $\mathrm{E} / \mathrm{A}$ & $0.88(0.78-0.96)$ & $0.88(0.79-0.98)$ & $0.98(0.8-1.1)$ & 0.14 & 0.33 \\
\hline DecT (msec) & $244(201-279)$ & $237(200-281)$ & $205(178-257)$ & 0.24 & 0.45 \\
\hline $\mathrm{E}^{\prime}$ wave lateral $(\mathrm{cm} / \mathrm{sec})$ & $8.5(8-10)$ & $10(9-11)$ & $11(9-13)$ & 0.15 & 0.26 \\
\hline $\mathrm{E}^{\prime}$ wave septum $(\mathrm{cm} / \mathrm{sec})$ & $8.5(7-9)$ & $8(7-9)$ & $9(8-10)$ & 0.14 & 0.24 \\
\hline $\mathrm{E} / \mathrm{E}^{\prime}$ & $6.9(6.1-9)$ & $6(5.7-7.2)$ & $5.5(4.6-6.6)$ & 0.05 & $0.04 \dagger$ \\
\hline TDI systolic velocity $(\mathrm{cm} / \mathrm{sec})$ & $11(10-13)$ & $10(10-11)$ & $11(11-13)$ & 0.04 & 0.06 \\
\hline Valvular disease mild/moderate & $23 / 30(76 \%)$ & $32 / 40(80 \%)$ & $14 / 20(75 \%)$ & 0.54 & 0.68 \\
\hline
\end{tabular}

The data for continuous variables are presented as medians ( $95 \%$ confidence interval), categorical variables as frequencies (\%). The statistical tests used were the Mann-Whitney test, the Kruskal-Wallis test, the Fisher exact test, and the chi-square test, as appropriate

$L A$, left atrial; $L V$, left ventricular; $R W T$, relative wall thickness; DecT, deceleration time; TDI, tissue Doppler imaging

${ }^{*} \mathrm{P}<0.05, \mathrm{~B}$ vs. A and $\mathrm{C} . \dagger \mathrm{P}<0.05, \mathrm{~A}$ vs. $\mathrm{C}$ 
Table 3 Predictors of left atrial enlargement

\begin{tabular}{lccccc}
\hline Predictors & $\mathrm{P}$ & Coefficient & Standard error & Odds ratio & $95 \% \mathrm{CI}$ \\
\hline Stiffness $>12.5 \mathrm{Kpa}$ & 0.006 & 1.36 & 0.49 & 3.92 & 0.67 \\
Hypertension & 0.46 & -0.39 & 0.52 & $1.57-10.40$ \\
T2DM & 0.47 & 0.44 & 0.63 & $0.24-1.90$ \\
Smoke & 0.14 & 0.71 & 0.49 & 0.04 & $0.45-5.41$ \\
MAP $(\mathrm{mmHg})$ & 0.24 & 0.02 & 0.02 & 1.02 & $0.98-1.08$ \\
BMI $\left(\mathrm{kg} / \mathrm{m}^{2}\right)$ & 0.21 & 0.07 & 0.05 & 1.07 & $0.95-1.20$ \\
\hline
\end{tabular}

Logistic regression analysis on the variables correlated to the presence of left atrium enlargement (cut-off of left atrial volume index of $28 \mathrm{~mL} / \mathrm{m}^{2}$ )

T2DM, Type 2 diabetes mellitus; MAP, mean arterial pressure; BMI, body mass index

Table 4 Characteristics of the subpopulation of liver disease based on the presence of endoscopic signs of portal hypertension

\begin{tabular}{|c|c|c|c|}
\hline Characteristics & Normal findings $(\mathrm{n}=24)$ & Pathological findings $(\mathrm{n}=25)$ & $\mathrm{P}$ \\
\hline Age (years) & $65(59-69)$ & $70(62-74)$ & 0.13 \\
\hline $\operatorname{Sex}(M: F)$ & $14: 10$ & 14:11 & 0.90 \\
\hline $\operatorname{BMI}\left(\mathrm{kg} / \mathrm{m}^{2}\right)$ & $24.5(24-27)$ & $25(23-27)$ & 0.84 \\
\hline Hypertension $(\mathrm{y} / \mathrm{n})$ & $11 / 24(46 \%)$ & $12 / 25(48 \%)$ & 0.89 \\
\hline $\mathrm{T} 2 \mathrm{DM}(\mathrm{y} / \mathrm{n})$ & $6 / 24(25 \%)$ & $5 / 25(20 \%)$ & 0.93 \\
\hline Smoke $(y / n)$ & $16 / 24(67 \%)$ & $10 / 25(40 \%)$ & 0.08 \\
\hline MAP (mmHg) & $99(94 / 105)$ & $97(90-107)$ & 0.70 \\
\hline HR (bpm) & $73(76-83)$ & $72(67-79)$ & 0.53 \\
\hline Stiffness (KPa) & $13.8(12-16)$ & $18(17-25)$ & 0.02 \\
\hline LA diameter $(\mathrm{cm})$ & $3.9(3.5-4.4)$ & $4.3(3.9-4.5)$ & 0.32 \\
\hline LA area $\left(\mathrm{cm}^{2}\right)$ & $20(16-21)$ & $20(18-22)$ & 0.14 \\
\hline LA volume index $\left(\mathrm{mL} / \mathrm{m}^{2}\right)$ & $29(25-34)$ & $27(23-35)$ & 0.78 \\
\hline End Diastolic LV Diameter (cm) & $4.45(4.3-4.6)$ & $4.9(4.6-5)$ & 0.01 \\
\hline Interventricular septum $(\mathrm{cm})$ & $1(1-1.2)$ & $1.1(1-1.2)$ & 0.51 \\
\hline Posterior wall $(\mathrm{cm})$ & $1(1-1.2)$ & $1.1(1-1.2)$ & 0.06 \\
\hline RWT & $0.45(0.42-0.48)$ & $0.48(0.41-0.50)$ & 0.68 \\
\hline LV indexed mass $\left(\mathrm{g} / \mathrm{m}^{2}\right)$ & $93(86-103)$ & $108(100-122)$ & 0.01 \\
\hline End diastolic LV volume (mL) & $99(80-118)$ & $116(101-124)$ & 0.16 \\
\hline Ejection fraction (\%) & $64(61-65)$ & $64(60-65)$ & 0.87 \\
\hline $\mathrm{E} / \mathrm{A}$ & $0.87(0.73-1)$ & $0.94(0.8-1)$ & 0.56 \\
\hline $\operatorname{DecT}(\mathrm{msec})$ & $204(178-299)$ & $261(215-290)$ & 0.33 \\
\hline E wave $(\mathrm{m} / \mathrm{sec})$ & $10(8-12)$ & $9(8-12)$ & 0.15 \\
\hline $\mathrm{E} / \mathrm{E}^{\prime}$ & $6(5-7)$ & $7(6-8)$ & 0.19 \\
\hline TDI systolic velocity $(\mathrm{cm} / \mathrm{sec})$ & $11(9-12)$ & $9(8-10)$ & 0.01 \\
\hline QTc (msec) & $432(425-454)$ & $440(419-457)$ & 0.63 \\
\hline
\end{tabular}

The data for continuous variables are presented as median (95\% confidence interval), categorical variables as frequencies (\%). The statistical tests used were the Mann-Whitney test, the Kruskal-Wallis test, the Fisher exact test and the chi-square test, as appropriate

$B M I$, body mass index; T2DM, Type 2 diabetes mellitus; MAP, mean arterial pressure; HR, heart rate; LA, left atrial; $L V$, left ventricular; RWT, relative wall thickness; DecT, deceleration time; TDI, tissue Doppler imaging; $y / n$, yes/no

Again, LS was not predictive for portal hypertension in logistic regression analysis $(\mathrm{P}=0.13)$. On the other hand, $\mathrm{S}^{\prime}$-wave velocity $(\mathrm{P}=0.02$, odds ratio $[\mathrm{OR}] 0.61,95 \% \mathrm{CI} 0.40-0.95), \mathrm{LV}$ mass ( $\mathrm{P}=0.04$, OR 1.05 95\%CI 1.0-1.1) and LA volume ( $\mathrm{P}=0.04$, OR $0.90,95 \%$ CI $0.82-0.99)$ were significantly associated with endoscopic findings of portal hypertension. 
Table 5 Predictors of portal hypertension

\begin{tabular}{lcccc}
\hline Predictors & P & Coefficient & Standard error & Odds ratio (95\%CI) \\
\hline Stiffness $(\mathrm{KPa})$ & 0.15 & 0.07 & 0.04 & $1.07(0.98-1.17)$ \\
End diastolic LV diameter $(\mathrm{cm})$ & 0.14 & 1.62 & 1.09 & $5.04(0.60-42.44)$ \\
LV indexed mass $\left(\mathrm{g} / \mathrm{m}^{2}\right)$ & 0.88 & 0.01 & 0.02 & $1.00(0.96-1.05)$ \\
TDI systolic velocity $(\mathrm{cm} / \mathrm{sec})$ & 0.04 & -0.53 & 0.25 & $0.59(0.36-0.97)$ \\
$\beta$-blockers use & 0.23 & 0.96 & 0.80 & $2.60(0.54-12.47)$ \\
\hline
\end{tabular}

Logistic regression analysis on the variables correlated with the presence of endoscopic signs of portal hypertension

$L V$, left ventricular; TDI, tissue Doppler imaging

\section{Discussion}

The present study indicates that echocardiographic parameters (LA volume, LV mass index and TDI $S^{\prime}$-wave velocity) may merit consideration as predictors of the presence of esophageal varices. These data need to be discussed in the light of the existing literature. We confirm that patients with compensated cirrhosis are characterized by a significantly larger left atrium, whether measured by AP diameter or by volume index; moreover, LS is the only independent predictor of LA enlargement. LA enlargement in cirrhotic patients has already been reported by Merli et al [19], in association with an increase in LV diameters, but not volumes. On the other hand, we did not find any difference in ventricular volumes or thicknesses, but the latter observation could have been partially biased by the exclusion from our cohort of alcoholic cirrhosis, which can be associated with altered LV diameters [20].

We failed to correlate the severity of liver fibrosis with diastolic function assessed by Doppler transmitral flow analysis, through parameters such as the E/A ratio, deceleration time and $E / E^{\prime}$. These parameters are notoriously affected by different factors, such as the overload state which is typical of cirrhosis, therefore mirroring a functional diastolic defect rather than a primary cardiac impairment [21]. On the other hand, the LA enlargement reflects the effects of increased filling pressures over time, independently of hemodynamic alterations, being a better indicator of chronic diastolic dysfunction. LA enlargement might be considered a diagnostic criterion of diastolic dysfunction in the course of cirrhotic cardiomyopathy; its accuracy as predictor of heart failure, ascites and hepatorenal syndrome in cirrhotic patients should be assessed by prospective studies.

When systolic function was assessed by conventional echocardiography, no significant differences in LV ejection fraction were observed between patients with chronic liver disease and controls. More complex techniques, such as TDI, were able to identify a reduction in the longitudinal peak systolic velocity $\left(\mathrm{S}^{\prime}\right)$ and to detect signs of early damage to $\mathrm{LV}$ longitudinal function in patients with chronic liver disease, even in earlier stages of fibrosis. Our results are similar to those obtained by Kazankov et al [22], who applied the ASE Guidelines as we did.

Concerning electrophysiological abnormalities, though we found a longer QTc in HCV-related liver diseases, no correlation was detected with the degree of liver fibrosis. The relationship between QTc prolongation and the severity of liver disease is still debated and it would be useful to rule out the possible impact of $\beta$-blockers in prospective studies [23].

Finally, we evaluated the association between echocardiographic and EGD findings. Nowadays, EGD is the screening method for all cirrhotic patients, since no other noninvasive techniques have shown a satisfactory predictive value for signs of portal hypertension, even though numerous studies have been conducted [24]. According to our data, the cardiovascular changes characteristic of cirrhotic cardiomyopathy appear to be closely related to the presence of esophageal varices. A reduction of the peak $S^{\prime}$-wave velocity on TDI, an increase in LV mass and LA dilatation could be early signs of portal hypertension, and thus may be useful for the early detection of patients with a higher risk of portal hypertension and associated complications. Furthermore, echocardiography seems to perform better as a predictor of endoscopic findings of portal hypertension compared to liver elastography. In fact, even though LS was significantly higher in patients with abnormal endoscopy, as already reported by other groups [18], when considered as a predictor in a more complex model including echocardiographic findings, it lost its significance. This is particularly relevant, suggesting that the $S^{\prime}$ wave could be considered a better and earlier predictor of portal hypertension than LS. It is possible that a more complex evaluation of heart function, including strain analysis, might provide further clues for the early detection of subclinical myocardial dysfunction in cirrhotic patients.

A major advantage of our study is the high homogeneity of the population; the restriction to HCV-related liver disease significantly reduced the impact of potential confounding factors, such liver disease etiology, which affected previous reports. Limitations of the present study include the relatively small sample size and the absence of a stress test (physical activity or pharmacological stress), which could have better disclosed subclinical systolic dysfunction. Finally, we still do not have prospective data on the follow up of patients affected by portal hypertension, which would help us evaluate the potential role of echocardiographic findings as prognostic markers.

In conclusion, our results show that LA enlargement and peak systolic velocity measured by TDI are suitable instruments for detecting diastolic and systolic dysfunction in chronic liver disease. In the absence of reliable methods to identify cirrhotic patients who should undergo endoscopy for screening of 


\section{Summary Box}

\section{What is already known:}

- Cirrhotic cardiomyopathy is a chronic condition of cirrhotic patients, characterized by blunted contractile responsiveness to stress and/or altered diastolic relaxation with electrophysiological abnormalities

- Many mechanisms may explain this condition: splanchnic arterial vasodilatation, hyperdynamic circulation, reduction in the effective arterial blood volume, activation of the renin-angiotensinaldosterone system and of the sympathetic nervous system, impaired response of $\beta$-adrenergic receptors, and increased production of endogenous cardiodepressant mediators

- Cirrhotic cardiomyopathy is associated with a worse prognosis, since it is related to heart failure, ascites, hepatorenal syndrome, and reduced survival after implantation of a transjugular intrahepatic portosystemic shunt

\section{What the new findings are:}

- Cirrhotic patients are characterized by a left atrium enlargement and by reduced systolic velocities recorded with tissue Doppler imaging (TDI)

- Reduction in the peak velocity of the $S^{\prime}$ wave on TDI, an increase in left ventricular mass, and left atrial dilatation are associated with the presence of esophageal varices

- Echocardiographic findings are potentially promising as an esophagogastroduodenoscopysparing strategy in screening for esophageal varices

esophageal varices, echocardiographic parameters might be worth considering.

\section{References}

1. Møller S, Henriksen JH. Cardiovascular complications of cirrhosis. Gut 2008;57:268-278.

2. Krag A, Bendtsen F, Mortensen C, Henriksen JH, Møller S. Effects of a single terlipressin administration on cardiac function and perfusion in cirrhosis. Eur J Gastroenterol Hepatol 2010;22:1085-1092.

3. Wong F. Cirrhotic cardiomyopathy. Hepatol Int 2009;3:294-304.

4. Bernardi M, Calandra S, Colantoni A, et al. Q-T interval prolongation in cirrhosis: prevalence, relationship with severity, and etiology of the disease and possible pathogenetic factors. Hepatology 1998;27:28-34.
5. Moller S, Henriksen JH. The systemic circulation in cirrhosis. In: Gines P, Arroyo V, Rodes J, Schrier RW (editors): Ascites and renal dysfunction in liver disease. Blackwell: Malden; 2005, pp. 139-155.

6. Ruiz-del-Árbol L, Serradilla R. Cirrhotic cardiomyopathy. World J Gastroenterol 2015;21:11502-11521.

7. Fede G, Privitera G, Tomaselli T, Spadaro L, Purrello F. Cardiovascular dysfunction in patients with liver cirrhosis. Ann Gastroenterol 2015;28:31-40.

8. Arroyo V, Terra C. Ruiz-del-Arbol L. Pathogenesis, diagnosis and treatment of ascites in cirrhosis. In: Rodés J, Benhamou JP, Blei AT, Reichen J, Rizzetto M (editors): Textbook of Hepatology: From Basic Science to Clinical Practice. $3^{\text {rd }}$ ed. Blackwell Publishing Ltd.: Oxford; 2008, pp. 666-710.

9. Ma Z, Meddings JB, Lee SS. Membrane physical properties determine cardiac beta-adrenergic receptor function in cirrhotic rats. Am J Physiol 1994;267:G87-G93.

10. Wiese S, Hove JD, Bendtsen F, Møller S. Cirrhotic cardiomyopathy: pathogenesis and clinical relevance. Nat Rev Gastroenterol Hepatol 2014;11:177-186.

11. Wiest R, Lawson M, Geuking M. Pathological bacterial translocation in liver cirrhosis. J Hepatol 2014;60:197-209.

12. Prabhu SD. Cytokine-induced modulation of cardiac function. Circ Res 2004;95:1140-1153.

13. Ruiz-del-Arbol L, Monescillo A, Arocena C, et al. Circulatory function and hepatorenal syndrome in cirrhosis. Hepatology 2005;42:439-447.

14. Merli M, Valeriano V, Funaro S, et al. Modifications of cardiac function in cirrhotic patients treated with transjugular intrahepatic portosystemic shunt (TIPS). Am J Gastroenterol 2002;97:142-148.

15. Ates F, Topal E, Kosar F, et al. The relationship of heart rate variability with severity and prognosis of cirrhosis. Dig Dis Sci 2006;51:1614-1618.

16. Poynard T, Ingiliz P, Elkrief L, et al. Concordance in a world without a gold standard: a new non-invasive methodology for improving accuracy of fibrosis markers. PLoS One 2008;3:e3857.

17. Devereux RB, Reichek N. Echocardiographic determination of left ventricular mass in man. Anatomic validation of the method. Circulation 1977;55:613-618.

18. Pritchett S, Cardenas A, Manning D, Curry M, Afdhal NH. The optimal cut-off for predicting large oesophageal varices using transient elastography is disease specific. J Viral Hepat 2011;18:e75-80.

19. Merli M, Calicchia A, Ruffa A, et al. Cardiac dysfunction in cirrhosis is not associated with the severity of liver disease. Eur J Intern Med 2013;24:172-176.

20. Milić S, Lulić D, Štimac D, Ružić A, Zaputović L. Cardiac manifestations in alcoholic liver disease. Postgrad Med J 2016;92:235-239.

21. Nagueh SF, Appleton CP, Gillebert TC, et al. Recommendations for the evaluation of left ventricular diastolic function by echocardiography. Eur J Echocardiogr 2009;10:165-193.

22. Kazankov K, Holland-Fischer P, Andersen NH, et al. Resting myocardial dysfunction in cirrhosis quantified by tissue Doppler imaging. Liver Int 2011;31:534-540.

23. Bal JS, Thuluvath PJ. Prolongation of QTc interval: relationship with etiology and severity of liver disease, mortality and liver transplantation. Liver Int 2003;23:243-248.

24. Garcia-Tsao G, Sanyal AJ, Grace ND, Carey W; Practice Parameters Committee of the American College of Gastroenterology. Prevention and management of gastroesophageal varices and variceal hemorrhage in cirrhosis. Hepatology 2007;46:922-938. 